\title{
Alcohol use among sixth-year medical students at the University of the Free State
}

\begin{abstract}
A L Marais, MB ChB
F J W Calitz, BA, HOD, MA, PhD

L U Z Rataemane, BA, MSC, MPhil
\end{abstract}

Department of Psychiatry, University of the Free State, Bloemfontein

G Joubert, BA, MSC

Department of Biostatistics, University of the Free State, Bloemfontein

Introduction. Excessive alcohol consumption among students is cause for concern, not only because medical students themselves may suffer in the long term but also because of the potential negative impact this may have on their effectiveness as tomorrow's doctors.

Objectives. The aim of the study was to investigate alcohol use among bth-year medical students at the University of the Free State (UFS) and reasons for their alcohol use.

Methods. After a compulsory lecture on an unrelated topic, the 6th-year medical students at the UFS were given a demographic questionnaire, the self-rated Alcohol Use Disorders Identification Test (AUDIT) and a shortened version of the selfrated Inventory of Drug-taking Situations (IDTS) to complete.

Conclusion. From the results of this study it is clear that a significant number of 6th-year medical students at the UFS (28.3\%) use alcohol in a harmful way. Most students use alcohol when they are with friends or in some kind of social setting. However, a number of students use alcohol to cope with stressful situations. It is therefore important that the prevention of harmful use of alcohol should receive attention in medical schools.
Excessive alcohol consumption among medical students is cause for concern, not only because medical students themselves may suffer in the long term but also because of the potential negative impact this may have on their effectiveness as tomorrow's doctors.' Doctors directly or indirectly influence the health of society through their clinical and preventive work, and by being perceived as role models for society. ${ }^{2}$ Unfortunately, doctors are recognised as being among the highest drinking professional groups, so the old saying that an alcoholic is someone who drinks more than his doctor has some foundation in reality. ${ }^{1,-6}$ The Health Committee of the Health Professions Council of South Africa (HPCSA) dealt with an average case load of 113 allegedly impaired doctors per month in 2000. Alleged drug or alcohol dependency in the year 2000 accounted for 72 cases. Seventytwo per cent of the doctors referred to the HPCSA's Health Committee for suspected impairment are younger than 50 years of age. ${ }^{7}$

One reason for the high level of alcohol consumption among medical students is the stress and strain of medical education. ${ }^{8}$ Students undertaking a career in medicine are generally high achievers with a demonstrated capacity to adapt to academic and time demands. It is often assumed that they will remain functional and unimpaired by using effective coping mechanisms. In reality, physicians are vulnerable to stress and symptom formation from the beginning of training and throughout their professional lives. This has adverse consequences for themselves, their families, and their patients. ${ }^{9}$

Medical training shares many characteristics with other graduate and professional programmes. The specific and unique components that distinguish medical training, however, have a significant impact on the life of the student. The rigidity and intensity of the medical training period from the first year through residency is unequalled. Other educational programmes may span the same number of years but they do not involve the same total and inflex- 
ible commitment of time and energy. ${ }^{9}$ The competitiveness of the medical school atmosphere as well as the academic pressures are experienced as stressful by most students. Most students adapt, others do not. For some, the conflicts may result in somatic formation, substance abuse, depression, anxiety, self doubt, academic difficulty, or family problems. ${ }^{10,11}$ Firth $^{12}$ also found that the practice of medicine entails certain risks to the mental health of both qualified doctors and students and a link between the training and later problems of mental health has been suggested.

Other stress factors identified by students in their training are talking to psychiatric patients, effects of the training on their personal life, presenting cases, dealing with death and suffering, and relationships with their consultants. ${ }^{12}$ Medical students also feel that certain personal and educational goals must be accomplished. These goals include: (i) the acquisition of a large body of medical information; (ii) the development of medical skills; (iii) the consolidation and integration of personal identity, and separation from family; (iv) the development of a professional identity; and ( $v$ ) the formulation of long-term career and life goals consistent with personal commitments and growth. The first-year student also starts medical school with the belief that there is a body of specific information to be learned that, with diligence, can be mastered. Great is the disappointment when the student realises that the material cannot be entirely mastered and that perfection is unattainable. ${ }^{13}$

These stress factors are complicated by the fact that the educational process occurs within a particular transitional developmental stage in the life of most students. It involves a shift from a position of dependency on others to one requiring the assumption of major responsibilities for others. Since the period of medical school usually also coincides with the late adolescent period of identity formation and its particular concerns, one may encounter the use of less mature defence mechanisms such as denial and projection. Students may displace their anxiety and blame instructors, the school, or the medical establishment. They may identify with patients and become angry with the dehumanisation they (and their patients) experience.?

According to Plant (in Ashton and Kamali ${ }^{14}$ ) the greatest single reason for the high alcoholism rate among doctors is the failure of medical training to make students as aware of their own problems as they should be of those of their patients. Benatar ${ }^{7}$ is of the opinion that medical students simply skip coping skills lectures in favour of concentrating on information that they need to know in order to pass the examinations. Benatar also said that medical students differ widely in their emotional ability to cope, something far more difficult to assess than intellectual capability. If students do not learn to cope with stress while in medical school the chances are that they will not be able to cope as qualified doctors, where stresses and responsibilities are so much greater. ${ }^{15}$

\section{Objectives}

The aim of the study was to investigate alcohol use among sixthyear medical students at the University of the Free State (UFS) and reasons for their alcohol use.

\section{Methods}

After a compulsory lecture on an unrelated topic, the sixth-year medical students at the UFS were given a demographic questionnaire, the self-rated Alcohol Use Disorders Identification Test (AUDIT), ${ }^{16}$ and a shortened version of the self-rated Inventory of Drug-taking Situations (IDTS) 17 to complete. The students also had to sign a consent form. The first author was present, explained the study to the students and stressed that the questionnaire was anonymous. The students did not know beforehand that the questionnaire would be administered.

The AUDIT was developed by the World Health Organisation to identify persons whose alcohol consumption has become hazardous to their health. The self-rated AUDIT is a 10-item screening questionnaire with 3 questions on the amount and frequency of drinking, 3 questions on alcohol dependence, and 4 on problems caused by alcohol. The minimum score (for non-drinkers) is 0 and the maximum possible score is 40 . A score of 8 or more indicates a strong likelihood of hazardous or harmful drinking. The IDTS measures the degree to which an individual drank heavily in a number of different situations over the past year.

The study was approved by the Ethics Committee of the Faculty of Health Sciences, UFS.

\section{Statistical Procedure}

To compare subgroups $95 \%$ confidence intervals $(\mathrm{Cls})$ were calculated for the differences between percentages. Differences are statistically significant when the $95 \% \mathrm{Cl}$ for a difference between percentages does not include the value zero. ${ }^{18}$

\section{Results}

Of 118 questionnaires distributed, 88 were received, giving an overall response rate of $74.6 \%$. The demographic data on the respondents are summarised in Table I. There was no significant difference between the response rates of the women (74. $1 \%)$ and men (75\%). 


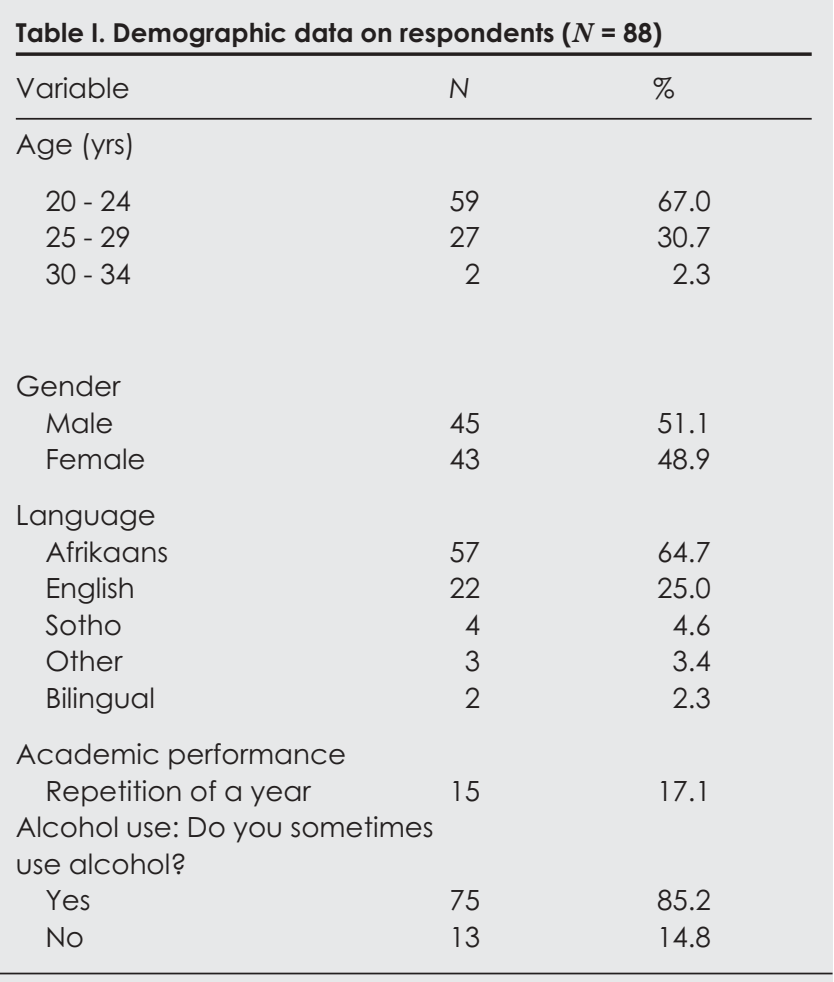

The majority of the students (85.2\%) stated that they sometimes used alcohol. However, of these students $4.5 \%$ responded as nondrinkers to the AUDIT and IDTS.

Table II includes all the questions asked in the AUDIT, and the responses expressed as percentages. More than one-quarter (28.3\%) of the respondents had a score of 8 or more, with the highest score being 20 . It was found that $33.3 \%$ of the male students had a score of 8 or more in comparison with $18.6 \%$ of the female students $(95 \% \mathrm{Cl}$ : males $-3.7 \%$, females $31.8 \%)$. The respondents who repeated one or more academic years and the respondents who did not were also compared with regard to their scores on the AUDIT. Nearly half of the respondents (46.7\%) who repeated a year had a score of 8 or more versus $21.9 \%$ of the respondents who did nor repeat a year (95\% Cl: $-1.6 \%, 50.4 \%)$, but this was not found to be statistically significant.

Table III lists the various situations given by the respondents for their use of alcohol. The only situation of alcohol use where there was a statistically significant difference between the response of the male and female students was when they felt tense or uneasy in the presence of someone. While none of the male students responded 'frequently' or 'almost always' to this situation, $14.0 \%$ of the female students' response was 'frequently' or 'almost always.' $(95 \% \mathrm{Cl}$ : females $2.9 \%$, males $24.2 \%)$.

\section{Discussion}

The authors could not find any other study conducted among medical students where the AUDIT was used as a marker for harmful drinking. The results of this study could serve as baseline figures for further descriptive and intervention studies.

Conard et al. ${ }^{19}$ included questions on the frequency of alcohol use but no questions on the amount of alcohol use in their study of fourth-year medical students. They found that $88 \%$ of students had used alcohol in the previous month and $9.1 \%$ of students used alcohol on a daily basis. One can compare these results with the results to question 1 of the AUDIT. When one combines the results of the students who used alcohol on a monthly basis, 2 or 4 times a month and 2 - 3 times a week, it adds up to $80.4 \%$, which is very similar to the $88 \%$ in the study by Conard et al. ${ }^{19}$ However, none of the students in our study used alcohol 4 or more times a week, compared with the 9.1\% of the students in the study by Conard et al. who used it on a daily basis.

Newbury-Birch ${ }^{20}$ investigated the quantity of alcohol used by 194 first-year medical students, as measured in units. The Health Education Council of the UK advises consumption of under 21 units a week for men and 14 for women, implying that consumption beyond this is harmful. One unit is equivalent to half a pint of beer, one measure of spirits, or a glass of wine or sherry. ${ }^{21} \mathrm{He}$ found that $45 \%$ of the students reported drinking above the recommended limits of alcohol consumption. In a study by Pickard et al. ${ }^{22}$ of second-year medical students at a university in the UK, $51 \%$ of the students exceeded the recommended limits of alcohol consumption. The results of these studies are significantly higher than the $28.3 \%$ of the respondents in our study who had a score of 8 or more on the AUDIT that is indicative of harmful drinking.

Because epidemiological research on drug abuse has established that men are more likely to be substance users, the male and female respondents were compared with regard to their total score on the AUDIT. Our results are comparable to those of a study by Ashton and Kamali. ${ }^{14}$ They measured harmful drinking by looking at the number of units of alcohol used by the students and found that $32.3 \%$ of the male students and $21.1 \%$ of the female students were drinking above the recommended minimum low-risk levels.

When one looks at the situations in which alcohol was used, it seems that social factors play the most important role. Most students drank when they were with friends or in some kind of social setting. However, there were also a number of students who used 
Table II. Results of the Alcohol Use Disorders Identification Test in percentages $(N=88)$

\begin{tabular}{|c|c|c|c|c|c|}
\hline \multirow[b]{2}{*}{ Question } & \multicolumn{5}{|c|}{ Frequency } \\
\hline & Never & Monthly & $\begin{array}{l}2 \text { or } 4 \\
\text { times a } \\
\text { month }\end{array}$ & $\begin{array}{l}2 \text { - } 3 \\
\text { times a } \\
\text { week }\end{array}$ & $\begin{array}{l}4 \text { or more } \\
\text { times a } \\
\text { week }\end{array}$ \\
\hline 1. How often do you have a drink containing alcohol? & 19.6 & 21.8 & 37.9 & 20.7 & 0.0 \\
\hline \multirow{2}{*}{$\begin{array}{l}\text { 2. How often do you have six or more drinks on one } \\
\text { occasion? }\end{array}$} & 56.8 & 25.0 & 15.9 & 2.3 & 0.0 \\
\hline & 1 or 2 & 3 or 4 & 5 or 6 & 7,8 or 9 & 10 or more \\
\hline \multirow{2}{*}{$\begin{array}{l}\text { 3. How many drinks containing alcohol do you have } \\
\text { on a typical day when you are drinking? }\end{array}$} & 42.4 & 39.1 & 9.2 & 5.8 & 3.5 \\
\hline & Never & $\begin{array}{l}\text { Less than } \\
\text { monthly }\end{array}$ & Monthly & Weekly & $\begin{array}{l}\text { Daily or } \\
\text { almost daily }\end{array}$ \\
\hline $\begin{array}{l}\text { 5. How often during the last year have you needed a } \\
\text { drink first thing in the morning to get yourself going } \\
\text { after a heavy drinking session? }\end{array}$ & 96.5 & 3.5 & 0.0 & 0.0 & 0.0 \\
\hline $\begin{array}{l}\text { 6. How often during the last year have you had a } \\
\text { feeling of guilt or remorse after drinking? }\end{array}$ & 76.7 & 19.8 & 2.3 & 1.2 & 0.0 \\
\hline $\begin{array}{l}\text { 7. How often during the last year have you been } \\
\text { unable to remember what happened the night } \\
\text { before because you had been drinking? }\end{array}$ & 72.7 & 22.7 & 4.6 & 0.0 & 0.0 \\
\hline $\begin{array}{l}\text { 8. How often during the last year have you } \\
\text { found you were not able to stop drinking once } \\
\text { you had started? }\end{array}$ & 77.2 & 14.8 & 8.0 & 0.0 & 0.0 \\
\hline $\begin{array}{l}\text { 9. Have you or someone else been injured because } \\
\text { of your drinking? }\end{array}$ & 92.1 & & 1.1 & & 6.8 \\
\hline $\begin{array}{l}\text { 10. Has a relative or friend, or a doctor or other health } \\
\text { worker been concerned about your drinking or } \\
\text { suggested you cut down? }\end{array}$ & 90.9 & & 0.0 & & 9.1 \\
\hline
\end{tabular}

alcohol when they were depressed about things in general, when they felt they had let themselves down, when they felt lonely or when they felt depressed or anxious about something. It therefore seems that the stresses and strains of medical education do play a role in the alcohol consumption of this group of medical students.

Zucker (in Babur et al. ${ }^{23}$ ) postulated that negative-affect alcoholism is a subtype of alcoholism. According to this hypothesis, women are more likely to use alcohol for mood regulation and to help ease social relationships. The male and female students were therefore compared with regard to situations in which alcohol was used.
The issue is often raised as to whether respondents to questionnaires on alcohol consumption accurately report their rates of alcohol use - it is possible that they underreport or overreport. However, a number of previous methodological studies have supported the validity of self-report questionnaires when administered anonymously. ${ }^{24}$

\section{Conclusion}

From the results of this study it is clear that a significant number of sixth-year medical students at the UFS (28.3\%) use alcohol in a harmful way. Most students use alcohol when they are with friends 
Table III. Results of the Inventory of Drug-taking Situations in percentages $(N=88)$

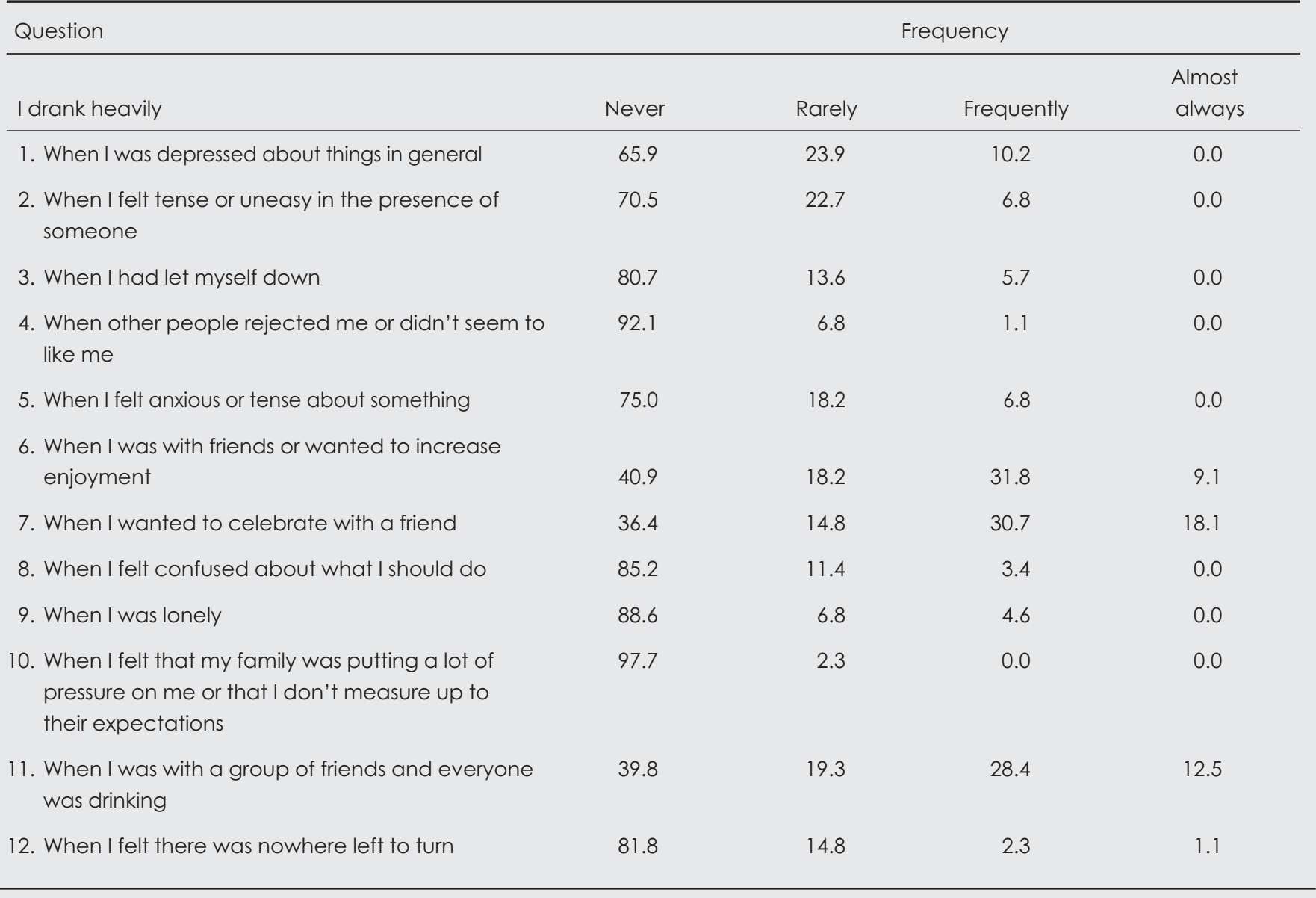

or in some kind of social setting. However, a number of students use alcohol to cope with stressful situations. It is therefore important that the prevention of harmful use of alcohol should receive attention in medical schools. Throughout their period of training, medical students should be given clear messages about school policy on alcohol, and they should be provided with appropriate educational materials. Medical schools should also make proper provision for student health care and support services, and ensure that those working in these services are properly trained in the identification and management of alcohol misuse. Furthermore, students should be taught how to cope with stress in a healthy way. They should be given the opportunity to talk to a tutor or a counsellor if they experience problems, whether these are related to their studies or their personal life. In this manner alcohol use as a way to cope with stressful situations should be prevented. By coping with stressful situations in a positive way, students will achieve personal growth, something that will be very important throughout their professional careers.

\section{References}

1. Wallace P. Medical students, drugs and alcohol: time for medical schools to take the issue seriously. Med Educ 2000; 34: 86-87.

2. Gray JD, Bhopal RS, White M. Developing a medical school alcohol policy. Med Educ 1998; 32: 138-142.

3. Brewster JM. Prevalence of alcohol and other drug problems among physicians. JAMA 1986 255: 1913-1920.

4. Hughes PH, Conard SE, Baldwin DC, Storr CL, Sheehan DV. Resident physician substance use in the United States. JAMA 1991; 265: 2069-2073.

5. Talbott GD, Gallegos KV, Wilson PO, Porter TL. The Medical Association of Georgia's Impaired Physicians Program. JAMA 1987; 57: 2927-2930.

6. Lloyd G. Alcoholic doctors can recover. BMJ 1990; 300: 728-730.

7. Bateman C. Doctor burnout silent and fatal. S Afr Med J 2001; 91: 98-100.

8. Gu hrie EA, Black D, Shaw CM, Hamilton J, Creed FH, Tomenson B. Embarking upon a medical career: psychological morbidity in firstyear medical students. Med Educ 1995; 29: 337-341.

9. Shapiro EC, Lowenstein LM. Becoming a Physician: Development of Values and Attitudes in Medicine. Cambridge, Massachusetts: Ballinger, 1979: 201-205.

10. Aktekin M, Karaman T, Senol YY, Erde MS, Erengin H, Akaydin M. Anxiety, depression and stressful life events among medical students: a prospective study in Antalya, Turkey. Med Educ $2001 ; 35(1): 12-17$.

11. Edwards M, Zimet C. Problems and concerns among medical students. Journal of Medical Education 1975; 51 : $619-625$.

12. Fir h J. Levels and sources of stress in medical students. BMI 1986; 292: $1177-1180$.

13. Boyle BP, Coombs RH. Personality profiles related to emotional stress in the initial year of medical training. Journal of Medical Education 1971; 46: 882-888. 
14. Ashton $\mathrm{CH}$, Kamali F. Personality, lifestyles, alcohol and drug consumption in a sample of British medical students. Med Educ 1995; 29: 187-192.

15. Heins M, Fahey SH. Perceived stress in medical, law, and graduate students. Journal of Medical Education 1984; 59: 169-179.

16. Allen JP, Colombus M. Assessing Alcohol Problems: A Guide for Clinicians and Researchers. Bethesda: National Institute on Alcohol Abuse and Alcoholism, 1995: 260-262.

17. Sajatovic M, Ramirez LF. Rating Scales in Mental Health. Ohio: Lexi-Comp Inc., 200 1: 264 270.

18. Gardner MJ, Altman DG. Statistics with Confidence - Confidence Intervals and Statistical Guidelines. London: BMJ, 1989: 15

19. Conard S, Hughes P. Substance use by fourth year students at 14 US medical schools. Journal of Medical Education 1988; 63: 747-757.
20. Newbury-Birch D, White $M$, Kamali F. Factors influencing alcohol and illicit drug use amongst medical students. Drug Alcohol Depend 2000; 59: 125-130.

21. Anderson $P$, Cremona $A$, Wallace $P$. What are safe levels of alcohol consumption? $B M$ 1984; 289: 1657-1658

22. Pickard $M$, Bales $L$, Donan $M$, et al. Alcohol and drug use in second year medical students a he University of Leeds. Med Educ 2000; 34: 148-150.

23. Babor TF, Hofmann M, DelBoca FK, et al. Types of alcoholics I: Evidence for an empirically derived typology based on indicators of vulnerability and severity. Arch Gen Psychiatry 1992; 49: 599-608.

24. King FW. Anonymous vs identifiable questionnaires in drug usage surveys. Am J Psychiatry 1970; 25: 982-985. 